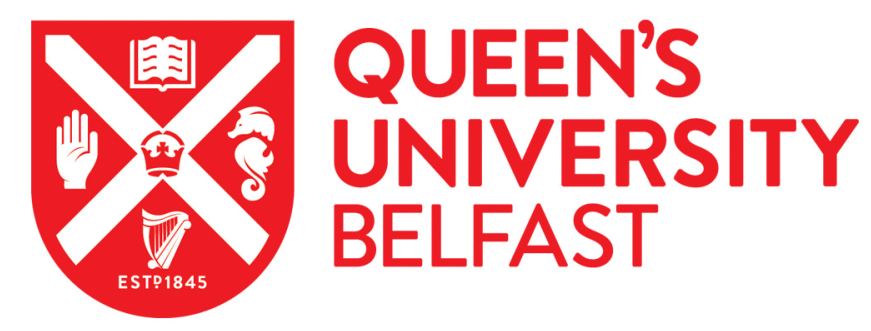

\title{
Compact Multi-Mode Quadrifilar Helical Antenna for GNSS-R Applications
}

Musthafa, A. M., Khalily, M., Araghi, A., Yurduseven, O., \& Tafazolli, R. (2022). Compact Multi-Mode Quadrifilar Helical Antenna for GNSS-R Applications. IEEE Antennas and Wireless Propagation Letters.

https://doi.org/10.1109/LAWP.2022.3144968

Published in:

IEEE Antennas and Wireless Propagation Letters

Document Version:

Peer reviewed version

Queen's University Belfast - Research Portal:

Link to publication record in Queen's University Belfast Research Portal

Publisher rights

(c) 2022 IEEE.

This work is made available online in accordance with the publisher's policies. Please refer to any applicable terms of use of the publisher.

\section{General rights}

Copyright for the publications made accessible via the Queen's University Belfast Research Portal is retained by the author(s) and / or other copyright owners and it is a condition of accessing these publications that users recognise and abide by the legal requirements associated with these rights.

Take down policy

The Research Portal is Queen's institutional repository that provides access to Queen's research output. Every effort has been made to ensure that content in the Research Portal does not infringe any person's rights, or applicable UK laws. If you discover content in the Research Portal that you believe breaches copyright or violates any law, please contact openaccess@qub.ac.uk. 


\title{
Compact Multi-Mode Quadrifilar Helical Antenna for GNSS-R Applications
}

\author{
Ashifa M. Musthafa, Mohsen Khalily, Senior Member, IEEE, Ali Araghi, Graduate Student Member, IEEE, \\ Okan Yurduseven, Senior Member, IEEE, and Rahim Tafazolli, Senior Member, IEEE
}

\begin{abstract}
In this paper, a compact circularly polarized (CP) multi-mode antenna for global navigation satellite system reflectometry (GNSS-R) is presented. The design comprises two Quadrifilar Helical Antennas (QHAs), each fed with a ground coplanar waveguide (GCPW) and quarter wavelength power divider (QWPD) integrated feed. A hybrid staircase-shaped (SSR) QHA radial is proposed, and it is formed by serially arranging several vertical and diagonal elements. The electric field lines from the vertical elements converge constructively to radiate with the axis normal. Besides, the circular spatial offsets between the adjacent diagonal and vertical elements induce a $90^{\circ}$ delay in the field radiated. This hybrid shape launches an unprecedented theory facilitating normal mode of operation (MOOp) in QHA and generates $\mathrm{CP}$ over broad elevations and azimuths $\left(0^{\circ}<\theta<\mathbf{8 0}^{\circ}\right.$ and $\left.0^{\circ}<\phi<\mathbf{3 6 0}^{\circ}\right)$. Besides, the port-to-port $90^{\circ}$ spatial offset and the GCPW architecture yield high isolation ( $>20 \mathrm{~dB})$. Unlike conventional GNSS-R antennas, this compact $(170.5 \mathrm{~mm} \times 132 \mathrm{~mm})$ configuration operates in axial and normal mode, offers a broad beam coverage $\left(237^{\circ}\right)$, minimizes pattern interference between the two QHAs upon gap-free stacking, and ensures high delay accuracy in the remote sensing data computed. Additionally, it supports proficient (efficiency $>0.9$ ) multi-constellation remote sensing. The design prototype was fabricated and measured, and the measurements agreed well with the simulations.
\end{abstract}

Index Terms-Circular polarization, Global Navigation Satellite System Reflectometry (GNSS-R), Quadrifilar Helical Antenna (QHA)

\section{INTRODUCTION}

G LOBAL Navigation Satellite Systems-Reflectometry (GNSS-R) is a real-time Microwave Remote Sensing (MRS) technique [1] - [2]. It has received much attention in recent years due to its capability to address wide-ranging applications and produce information with a high spatial resolution [1], [3]- [4]. The GNSS-R system consists of two antennas (conjointly addressed as GNSS-RAP), two recorders, and a processing software [5]. According to its operation principle, the correlation between received direct (D-GNSS) and ground-reflected GNSS (R-GNSS) signals are exploited to infer the physical composition of the reflected surface [6]. But, the D-GNSS signal is polarization flipped (right-hand circular polarization (RHCP) to left-hand CP (LHCP)) upon reflection

Ashifa M. Musthafa was with the ICS and is currently with the Department of Electronics, Information and Bioengineering (DEIB), Politecnico Di Milano, 20133 Milan, Italy, Email: (ashifa0430@gmail.com). Mohsen Khalily, Ali Araghi, and Rahim Tafazolli are with the Institute for Communication Systems (ICS), Home of the 5G \& 6G Innovation Centres (5GIC \& 6GIC), University of Surrey, Guildford, GU2 7XH, United Kingdom, Email: ( m.khalily, a.araghi, r.tafazolli\}@surrey.ac.uk). Okan Yurduseven is with the Centre for wireless innovation, Queen's University Belfast, United Kingdom, Email: (okan.yurduseven@qub.ac.uk).
[2]. Conventionally, a GNSS-RAP comprises CP L-Band (1-2 $\mathrm{GHz}$ ) operated antennas [7]. Nonetheless, a compact GNSSRAP aids portability and a tight emplacement of its antennas ensure high delay accuracy in the sensed data [8].

Previously, the number of GNSS-R Antennas developed is limited, so few GNSS antennas reported will be reviewed for their compatibility of integration into the GNSS-R system [5], [9]- [12]. A tapered helix antenna in [5] and a 5turn bifilar helix antenna in [9] had massive structures and limited the system mobility upon integration. An annular ring microstrip antenna in [10] is fed with a microstrip (MS) feed line and is vulnerable to pattern interference and degradation upon tight emplacement into the GNSS-R system. A printed linearly polarized Yagi-Uda GNSS antenna in [11] suffers a high polarization loss factor due to misalignment between the incoming and designated radiation polarization, and if integrated, will make the system unreliable for real-time operations. In [12], a reduced-surface-wave GNSS antenna fed by proximity coupled probe (PCP) exhibits a narrow half power beamwidth (HPBW) and reduces its potential to capture from the GNSS satellites.

In this paper, we propose a GNSS-RAP. The configuration consists of two Quadrifilar Helical Antennas (QHAs), each fed with ground coplanar waveguide (GCPW) - Quarter Wavelength Power Divider (QWPD) integrated feed. The feeding networks of QHAs are aligned perpendicular to each other, launching orthogonal field vectors. The GCPW configuration latches the traveling electric-field (E-field) lines between its ground plates and prevents field leakage between the QHAs. The GCPW and the $90^{\circ}$ spatial port offset in the proposed design support mutual coupling reduction and enable the gap-free construction of two QHAs. Besides, this GNSS-RAP operates in dual mode (axial and normal). The strategically assembled and spaced (equidistant from its adjacent self) elements in the hybrid Staircase Shaped Radials (SSR) shown in Fig. 1 helps obtain a normal mode of operation (MOOp) with low elevated $\mathrm{CP}$ (on the transversal plane at $0^{\circ}<\theta<80^{\circ}$ ). The delay lines in QWPD induce a $90^{\circ}$ phase offset in power fed to the QHA radials, and the folding of QWPD delay lines aid miniaturization. Ultimately, as a GNSS-RAP, the antenna is a sound candidate for this application due to its dual MOOp, compact size, and gap-free configuration.

\section{Antenna Design And Configuration}

\section{A. Antenna Design}

Fig. 1 depicts the proposed GNSS-RAP configuration. The structure (exploded view presented in Fig. 1 (a)) consists of 


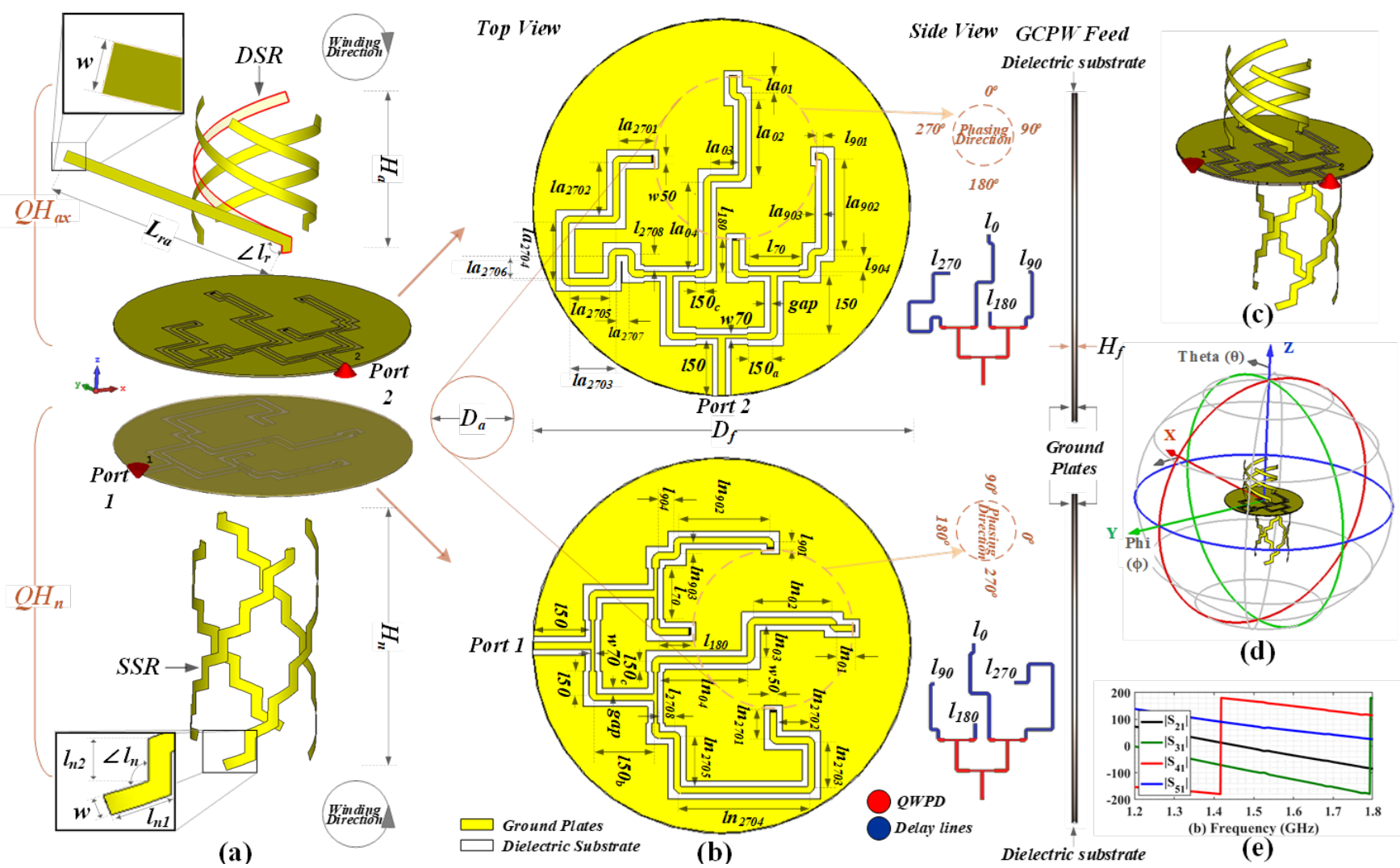

Fig. 1. The proposed GNSS-RAP configuration (a) Composition (b) Feed Geometry (c) Perspective view (d) Farfield plot coordinates (e) Simulated phase shift between delay lines at GPS L1 $(1.575 \mathrm{GHz})$. $\left|\mathrm{S}_{21}\right|$ represents $0^{\circ},\left|\mathrm{S}_{51}\right|$ represents $90^{\circ},\left|\mathrm{S}_{41}\right|$ represents $180^{\circ}$ and $\left|\mathrm{S}_{31}\right|$ represents $270^{\circ}$.

two QHAs $\left(Q H_{a x}\right.$ and $\left.Q H_{n}\right)$, each fed by a GCPW-QWPD feed. $Q H_{a x}$ operates in axial mode to capture D-GNSS and $Q H_{n}$ in normal mode to captures R-GNSS. Conventional helix radiates along its axis when its circumference $(\mathrm{C})$ is around one wavelength [13], so the QHA's C is chosen to be 0.94 wavelengths $(180 \mathrm{~mm})$. Each QHA accommodates four radials (SSR and Diagonal Shaped Radial (DSR)), equidistant from one another placed circularly over its corresponding feed. The $S S R$ (in $Q H_{n}$ ) composes segments of length $l_{n 1}$ and $l_{n 2}$, and $D S R$ in $Q H_{a x}$ is of length, $L_{r a}$. The $D S R$ enables $Q H_{a x}$ to radiate $\mathrm{CP}$ signals along the axis (axial-mode). Whereas, $S S R$ made two mighty contributions: First, by the reconstruction of the top view circular geometry of non-fed radials on the side of the structure with the combination of vertical and diagonal elements $\left(l_{n 2}\right.$ and $\left.l_{n 1}\right)$, the trace of a circular electric field is induced with a relative phase-shifted signal on the axis normal; second, by the sum of electric fields radiated by the short vertical elements $\left(l_{n 2}\right)$, normal-moded radiation is produced. These SSRs and DSRs are excited by the feed.

Fig. 1 (b) outlines the feed network. The GCPW feed structure comprises a dielectric substrate (Rogers RT5880 with $\epsilon_{r}=2.2$ and thickness $=0.787 \mathrm{~mm}$ ) sandwiched by three metal (copper) ground plates. The QWPD with delay lines is embedded on the underlying dielectric substrate. The QWPD equally divides the power with lines of widths, $w 70(70 \Omega)$ and $w 50(50 \Omega)$. The delay lines (namely, $l a_{0}, l a_{90}, l a_{180}, l a_{270}$, $\left.l n_{0}, l n_{90}, \ln _{180}, l n_{270}\right)$ induce a $90^{\circ}$ phase delay in the power fed to the radials and the delay pattern (progressive/regressive)
TABLE I

GEOMETRICAL PARAMETERS

\begin{tabular}{||c|c||c|c||c|c||c|c||}
\hline$H_{a}$ & 62.7 & $l 50_{c}$ & 3 & $l n_{03}$ & 11.02 & $l a_{2702}$ & 18.64 \\
$H_{n}$ & 106.2 & $l_{70}$ & 18 & $l n_{04}$ & 30.87 & $l a_{2703}$ & 18.29 \\
$H_{f}$ & 0.789 & $\mathrm{w} 70$ & 1.45 & $l_{90}$ & 40 & $l a_{2704}$ & 19.42 \\
$D_{a}$ & 57.3 & $w 50$ & 2.53 & $l_{901}$ & 1.71 & $l a_{2705}$ & 13.89 \\
$D_{f}$ & 132 & $g a p$ & 2 & $l a_{902}$ & 31.1 & $l a_{2706}$ & 7.96 \\
$w$ & 5 & $l_{0}$ & 74 & $l a_{903}$ & 2.1 & $l a_{2707}$ & 4.25 \\
$L_{r a}$ & 140.25 & $l a_{01}$ & 5.95 & $l_{904}$ & 5 & $l_{2708}$ & 5 \\
$\angle l_{n}, \angle l_{r}$ & 115 & $l a_{02}$ & 26.96 & $l n_{902}$ & 30.1 & $l n_{2701}$ & 8 \\
$l_{n 1}$ & 14.75 & $l a_{03}$ & 9.91 & $l n_{903}$ & 3.06 & $l n_{2702}$ & 10.78 \\
$l_{n 2}$ & 10.7 & $l a_{04}$ & 31.18 & $l_{180}$ & 10.8 & $l n_{2703}$ & 14.06 \\
$l 50$ & 20 & $l n_{01}$ & 5.75 & $l_{270}$ & 99 & $l n_{2704}$ & 44.41 \\
$l 50_{a}$ & 8 & $l n_{02}$ & 26.35 & $l a_{2701}$ & 11.50 & $l n_{2705}$ & 16.81 \\
\end{tabular}

defines the radiation mode (end-fire / back-fire mode). Unlike, the conventional microstrip line feed, the diverging E-field on the feed line is sandwiched by the GCPW's ground plates, latching them in the feed, preventing E-field leakage from one QHA to the other, and decreasing the mutual coupling between the QHA's. Besides, as observed from Fig. 1 (c), the ports aligned perpendicular to each other provide orthogonality in the field vector, isolating the two ports and reducing the mutual coupling even further. Table I presents the geometrical parameters of the configuration.

\section{B. Parametric study}

This subsection identifies the key factors affecting GNSSRAP radiation performance and provides design guidelines. 


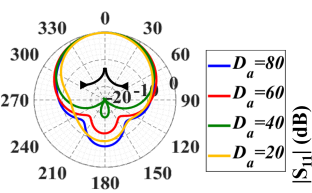

(a) $\theta /$ degree
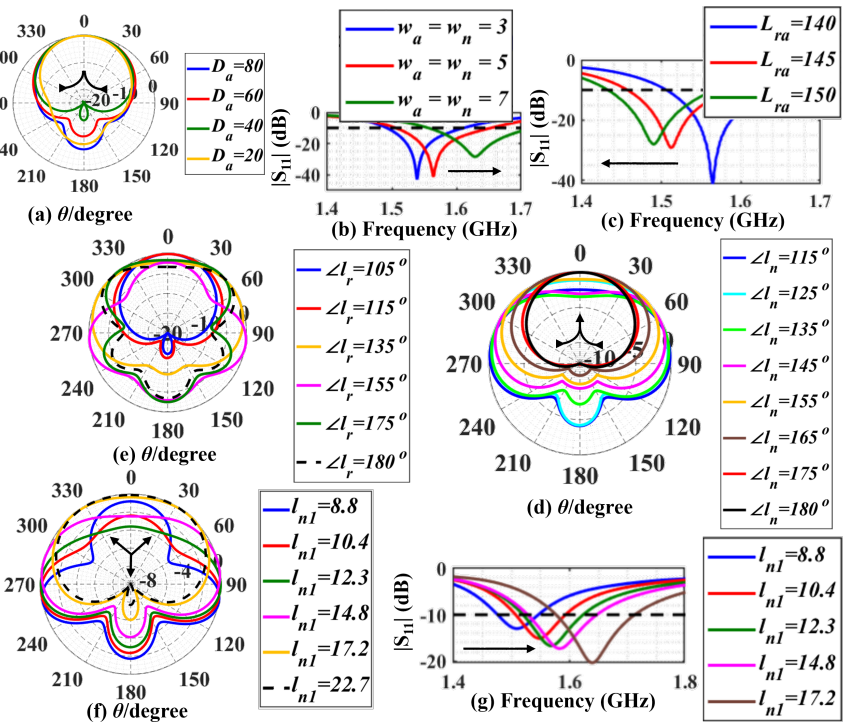

quency $(\mathrm{GHz})$

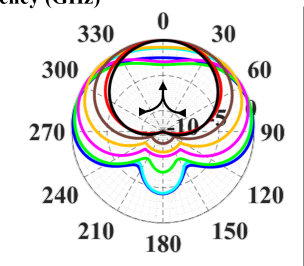

$-\angle l_{n}=115^{\circ}$

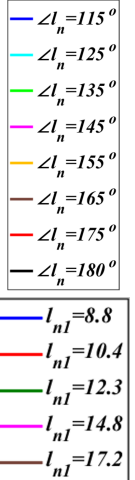

Fig. 2. Parametric analysis, effect of (a) $D_{a}$ (mm) on RP (b) $w_{a}$ (mm) and $w_{n}(\mathrm{~mm})$ on $\left|\mathrm{S}_{11}\right|$ (c) $L_{r a}(\mathrm{~mm})$ on $\left|\mathrm{S}_{11}\right|$ (d) $\angle l_{n}$ on RP (e) $\angle l_{r}$ on RP (f) $l_{n 1}(\mathrm{~mm})$ on $\mathrm{RP}(\mathrm{g}) l_{n 1}(\mathrm{~mm})$ on $\left|\mathrm{S}_{11}\right|$

The study in Fig. 2 (a)-(g) corresponds to QHA without GCPW-QWPD feed. Fig. 2 (a) shows that the change of $D_{a}$ has no influence on the QHA's MOOp and that its radiation remains intact. Fig. 2 (b) indicates that the impedance bandwidth widens, when $\left(w_{a} / w_{n}\right)$ increases. Fig. 2 (c) signifies that the antenna center frequency shifts higher when constructed with a $D S R$ lower than $150 \mathrm{~mm}$. With Fig. 2 (d), it is observable that with the change of $\angle L_{n}$ from $115^{\circ}$ to $180^{\circ}$, the main beam gradually alters from $\theta=90^{\circ}$ to $\theta=0^{\circ}$. The aforementioned shows the influence of the SSR's vertical element $\left(1_{n 2}\right)$ to excite normal MOOp in the $Q H_{n}$. The $Q H_{n}$ can be made to resonate at a frequency higher by increasing $l_{n 1}$ from $8.8 \mathrm{~mm}$ to 17.2 $\mathrm{mm}$, as demonstrated with Fig. 2 (g). It must be noted that the $l_{n 1}$ value in Fig. 2 (f) and (g) were altered, while the overall radial length of $Q H_{n}$ and $l_{n 2}$ were kept unaltered. Thus, in conclusion, the study implied the following. The QHA's $D_{a}$ has no effect on its MOOp and HPBW, while the SSR's $\angle l_{n}$ plays an intricate role in altering its MOOp and HPBW. The $Q H_{n}$ structure can be constructed for other applications with the following guidelines. The frequency of operation of both antenna's can be altered by tuning the radial width $\left(w_{a} / w_{n}\right)$ or radial overall length $\left(L_{r a}\right)$. Alternatively, $l_{n 1}$ contributes in the structure's operating frequency, which can modified while maintaining $L_{r a}$. Additionally, the bandwidth can be widened by tuning $w_{a} / w_{n}$, whereas the $L_{r a} / l_{n 1}$ is chosen corresponding to the band of interest. With the variation in $\angle l_{n}$. A variety of RP can be realized by tuning $\angle l_{r}, \angle l_{n}$,

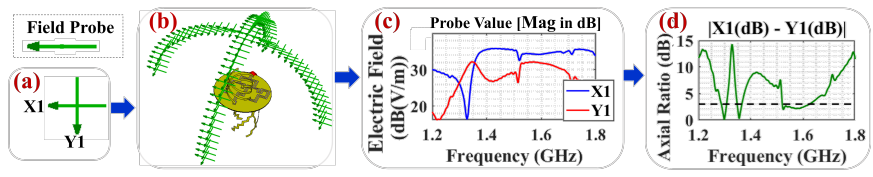

Fig. 3. Elaborated Axial Ratio Calculation
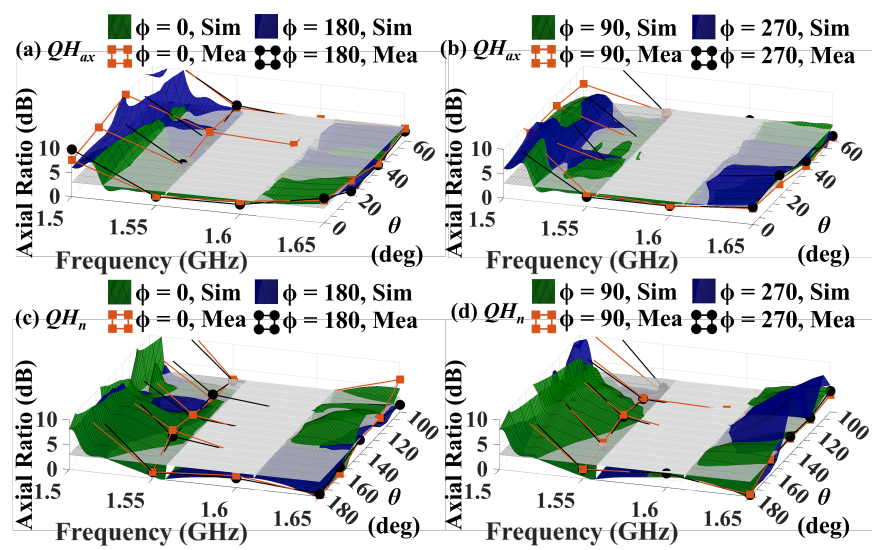

Fig. 4. Axial Ratio Plot (a), and (b) for $Q H_{a x}$. (c), and (d) for $Q H_{n}$.

and $l_{n 1}$ according to Fig. 2 (d), (e), and (f). For instance, the HPBW and the MOOp of the antenna can be set differently by rotating the $\angle l_{n}$ while maintaining the operating frequency.

\section{RESUlTS AND DISCUSSION}

In order to simulate the designed structure, the full-wave package CST Microwave Studio is used in this paper. To ease out AR calculation for this asymmetric structure, the AR calculation is done by employing perpendicularly aligned Efield probes (see Fig. 3 (a)) around the structure (see Fig. 3 (b)). The probe values (obtained from Fig. 3 (c)) are used to calculate axial ratio (adopting to method in Fig. 3 (d)) in this work. Fig. 4 reports the measured and simulated AR plot, representing an AR bandwidth (ARBW) at broadside and off-broadside directions. The ARs are reported at $\theta=$ $0^{\circ}, 90^{\circ}, 180^{\circ}$, and $270^{\circ}$ in frequency $=1.5 \mathrm{GHz}, 1.55 \mathrm{GHz}$, $1.6 \mathrm{GHz}$, and $1.65 \mathrm{GHz}$. The simulation agrees well with the measurement. A CP is obtained over the elevations spanning $\pm 60^{\circ}\left(Q H_{a x}\right)$ and $\pm 80^{\circ}\left(Q H_{n}\right)$ and at azimuths traversing the entire perigon in both QHAs. This multi-directional CP offers flexibility in capturing angles.

The E-field distribution is displayed in Fig. 5. As observed in Fig. 5 (a), the field produced by $Q H_{a x}$ is maximum along its axis, while for $Q H_{n}$, it is directed normal to the axis (in the
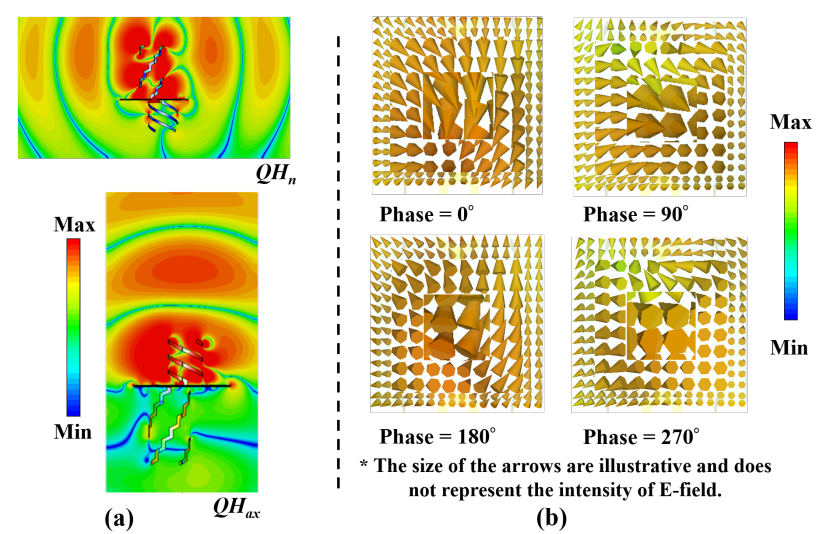

Fig. 5. E-Field distribution at GPS L1 (1.575 GHz) (a) Magnitude (b) E-field vector Plot on SP. 


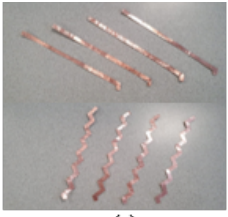

(a)

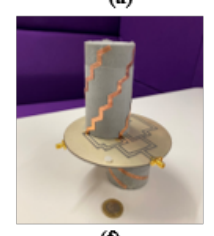

(f)

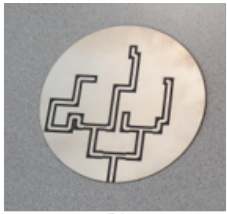

(b)

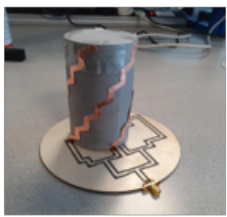

(e)

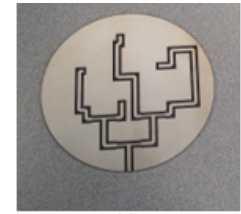

(c)

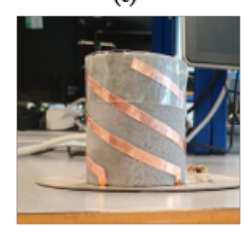

(d)
Fig. 6. Fabrication Process (a) DSRs (in top) and SSRs (in bottom) (b) $Q H_{a x}$ feed. (c) $Q H_{n}$ feed. (d) $Q H_{a x}$ (e) $Q H_{n}$ (f) GNSS-RAP.

transverse plane) and agrees well with analysis in Fig. 2 (d). A study on the $Q H_{n}$ 's polarization is conducted by introducing vacuum planes in a simulation environment. The plots of the E-field vector (see Fig. 5 (b)) present the direction of vector rotation at four phases. The vector rotates as the phase varies from $0^{\circ}$ to $270^{\circ}$. This rotation reported proves that the top view circular geometry of QHA is being mimicked on the side with an SSR arrangement. This circular placement on the side aided in producing wide axial ratio beamwidth (3dB-BW).

Fig. 6 summarizes the fabrication process of the proposed GNSS-RAP, and the outline of the steps is as follows. Initially, the DSRs and SSRs (in Fig. 6 (a)) are soldered and joined to their respective feeds (in Fig. 6 (b) and (c)). Then, as disclosed in Fig. 6 (d) and (e), the radials are wrapped around the foam cylinder $\left(\epsilon_{r} \approx 1\right)$ and stabilized. Eventually, $Q H_{a x}$ and $Q H_{n}$, with a $90^{\circ}$ spatial offset maintained between ports, are fastened together with plastic bolts and nuts, as disclosed in Fig. 6 (f). The gap-free emplacement of $Q H_{a x}$ and $Q H_{n}$ ensures a higher delay accuracy in the GNSS-R data. The compact size (170.5 $\mathrm{mm} \times 132 \mathrm{~mm}$ ) and the low profile grant unlimited mobility and eases its integration into automobiles, drones, etcetera.

The S-Parameters in Fig. 7 validates operation over the entire GNSS upper L-band. The measured bandwidth for $Q H_{a x}$ and $Q H_{n}$ is $1.5 \mathrm{GHz}-1.8 \mathrm{GHz}(300 \mathrm{MHz})$ and $1.44-1.8$ $\mathrm{GHz}(360 \mathrm{MHz})$ with $\left|\mathrm{S}_{22}\right|$ and $\left|\mathrm{S}_{11}\right|<-10 \mathrm{~dB}$. Lastly, mutual coupling $\left(\left|\mathrm{S}_{21}\right|\right.$ and $\left.\left|\mathrm{S}_{12}\right|\right)$ between $Q H_{a x}$ and $Q H_{n}$ is $<-20 \mathrm{~dB}$ across the operating band, implying its relative suppression.

The normalized radiation patterns are in Fig. 8. The farfield pattern displays a simulated HPBW of $105.5^{\circ}$ and $237^{\circ}$

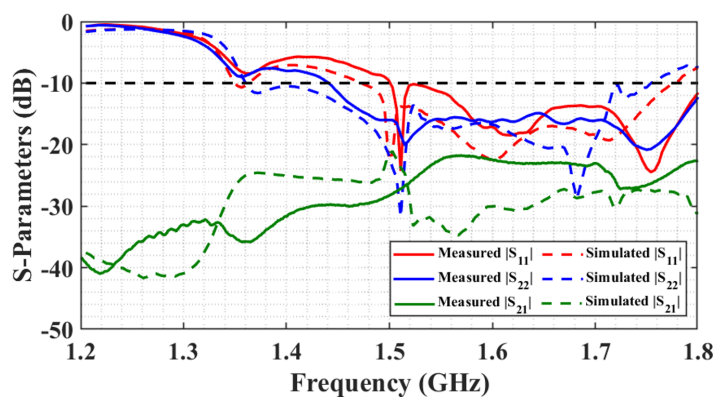

Fig. 7. Simulated and measured S-Parameter.

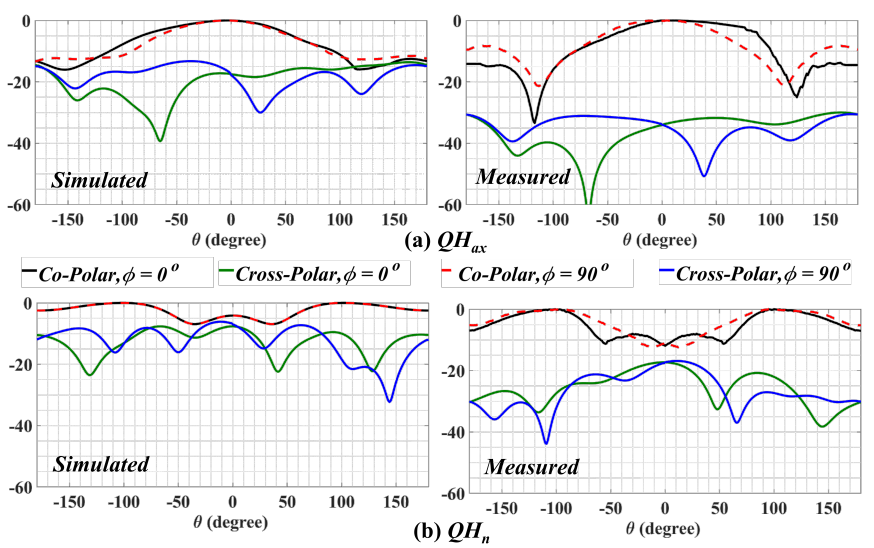

Fig. 8. Simulated and measured normalized radiation patterns (Co-Polar and Cross-Polar) at GPS L1 (1.575 GHz) of (a) $Q H_{a x}$ and (b) $Q H_{n}$.

for $Q H_{a x}$ and $Q H_{n}$. The measured cross-polarization rejection is $-32 \mathrm{~dB}$ and $-21 \mathrm{~dB}$ in $Q H_{a x}$ and $Q H_{n}$ over the HPBW. Besides, a measured front-back $(\mathrm{F} / \mathrm{B})$ radiation ratio of 10.1 $\mathrm{dB}$ (in $Q H_{a x}$ ) and $12.2 \mathrm{~dB}$ (in $Q H_{n}$ ) is recorded. The efficiency plot in Fig. 9 reports an in-band efficiency higher than 0.85 . The reported efficiencies are measured based on the Directivity/Gain method presented in [14]
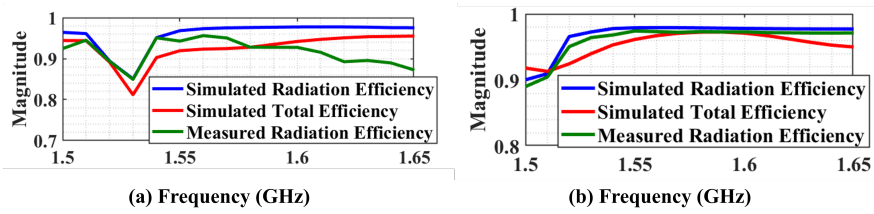

Fig. 9. Simulated and measured efficiency of (a) $Q H_{a x}$ (b) $Q H_{n}$.

The comparison of antenna metrics of $Q H_{n}$ with other QHA are shown in Table II. It compares the MOOp, HPBW, and $3 \mathrm{~dB}-\mathrm{BW}$ of various radial shapes with $S S R$. It is explicit that only $Q H_{n}$ works in normal mode but has relatively the same or lesser 3dB-BW than others. However, $Q H_{n}$ has the highest HPBW among QHA's in Table II.

TABLE II

PERFORMANCE SUMmary

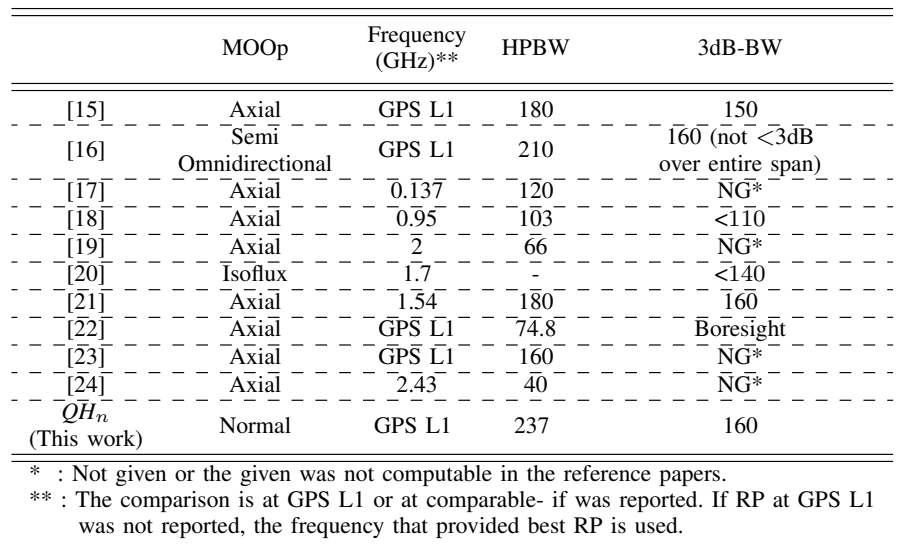




\section{REFERENCES}

[1] K. Yu, Y. Li, and X. Chang, "Snow Depth Estimation Based on Combination of Pseudorange and Carrier Phase of GNSS Dual-Frequency Signals," IEEE Trans. Geosci. Rem. Sens., Mar. 2019.

[2] T.Beltramonte, P. Braca, M.D. Bisceglie, A. Simone, C. Galdi, A. Iodice, L. M. Millefiori, D. Riccio, and P. Willett, "Simulation-Based Feasibility Analysis of Ship Detection Using GNSS-R Delay-Doppler Maps," IEEE J. Sel. Topics Appl. Earth Observ. Rem. Sens., Mar. 2020.

[3] F. Wang, D. Yang, and B. Zhang, "Geometric Distortion Correction of Spaceborne GNSS-R Delay-Doppler Map Using Reconstruction," IEEE Trans. Geosci. Rem. Sens., vol. 15, Dec. 2018.

[4] J. Mashburn, P. Axelrad, S.T. Lowe, and K.M. Larson, "Global Ocean Altimetry With GNSS Reflections From TechDemoSat-1," IEEE Trans. Geosci. Rem. Sens., vol. 56, Apr. 2018.

[5] M. Berg, R. Lighari, J. Kallankari, M. Majava, A. Pärssinen, E. Salonen, "Polarization Based Measurement System for Analysis of GNSS Multipath Signals," in 2016 10th European Conference on Antennas and Propagation (EuCAP), Davos, Switzerland, April 2016.

[6] C. Hu, C.R. Benson, L. Qiao, and C. Rizos, "The Validation of the Weight Function in the Leading-Edge-Derivative Path Delay Estimator for Space-Based GNSS-R Altimetry," IEEE Trans. Geo. R. Sen., 2020.

[7] A. Bibaut J.-C. Auber and J.- M. Rigal, "Characterization of multipath on land and sea at GPS frequencies". in Proc. 7th Int. Meet. Satell. Div. Inst. Navig. (ION GPS) Vol. 3(No. 2), September 1994.

[8] F. Huang, J.L. Garrison, S.M. Leidner, B. Annane, R.N. Hoffman, G. Grieco, and A. Stoffelen, "A Forward Model for Data Assimilation of GNSS Ocean Reflectometry Delay-Doppler Maps," IEEE Trans. Geosci. Remote Sens., Jun. 2020.

[9] B.T. Strojny, and R.G. Rojas, "Bifilar Helix GNSS Antenna for Unmanned Aerial Vehicle Applications," IEEE Ant. Wirel. Prop. Let., 2014.

[10] Y.-Q. Zhang, X. Li, L. Yang, and S.-X. Gong, "Dual-Band Circularly Polarized Annular-Ring Microstrip Antenna for GNSS Applications," IEEE Antennas Wireless Propag. Lett., vol. 12, 2013.

[11] H.C. Huang, J.C. Lu, and P. Hsu, "A Compact Dual-Band Printed YagiUda Antenna for GNSS and CMMB Applications," [11] Transmission Systems for Communications, vol. 63, no. 5, pp. 2342-2348, 2015.

[12] H.M. Liu, S. Fang, and Z.B. Wang, "A Novel Multimode ReducedSurface-Wave Antenna for GNSS Applications," IEEE Ant. Wirel. Prop. Lett., vol. 12, 2013.

[13] John L. Volakis, "Helical Antennas," in Antenna Engineering Handbook, 4th ed. NY, USA: McGraw-Hill, ch. 12, sec. 12.1, 2007.

[14] Y.Huang, "Radiation efficiency measurements of small antennas," in Handbook of Antenna Technologies, Z.N. Chen, D.Liu, H. Nakano, X. Qing, and T.Zwick, Eds. Singapore: Springer, 2016, pp. 2165-2189.

[15] M. Caillet, M. Clenet, A. Sharaiha, and Y. Antar, "A Broadband Folded Printed Quadrifilar Helical Antenna Employing a Novel Compact Planar Feeding Circuit," IEEE Trans. Antennas Propag., vol. 58, July. 2010.

[16] Y. Han, H. Wang, Z. Wang, Y. Yao, Y. Feng, K. Hu, Y. Gao, Z. Fan, and S. Yuan, "Dual-band Spiral Printed Quadrifilar Helical Antenna Miniaturized by Surface and Inner Dielectric Loading," IEEE Access., vol. 7, Feb. 2019.

[17] A. Takacs, N.J.G. Fonseca, and H. Aubert, "Height Reduction of the Axial-Mode Open-Ended Quadrifilar Helical Antenna," IEEE Ant. Wirel. Prop. Lett., vol. 9, 2010.

[18] X. Yi, L. Huitema, and H. Wong, "Polarization and Pattern Reconfigurable Cuboid Quadrifilar Helical Antenna," IEEE Trans. Ant. Prop., Jun. 2018.

[19] D.K.C. Chew and S.R. Saunders, "Meander Line Technique for Size Reduction of Quadrifilar Helix Antenna," IEEE Antennas Wireless Propag. Lett., vol. 1, 2002.

[20] S. Hebib, N.J. G. Fonseca, and H. Aubert, "Compact Printed Quadrifilar Helical Antenna With Iso-Flux-Shaped Pattern and High CrossPolarization Discrimination," IEEE Ant. Wirel. Prop. Lett., 2011.

[21] J. Rabemanantsoa and A. Sharaiha, "Size Reduced Multi-Band Printed Quadrifilar Helical Antenna," IEEE Trans. Antennas Propag., 2011.

[22] G. Byun, H. Choo, and S. Kim, "Design of a Dual-Band Quadrifilar Helix Antenna Using Stepped-Width Arms," IEEE Trans. Ant. Prop., Jan. 2015.

[23] S. Khajepour, M. S. Ghaffarian and G. Moradi, "Design of novel multiband folded printed quadrifilar helical antenna for GPS/WLAN applications," Elect. Let., vol. 53, Jan. 2017.

[24] M.F.B.Mansor, T. W. C. Brown, and B. G. Evans, "Satellite MIMO Measurement With Colocated Quadrifilar Helix Antennas at the Receiver Terminal," IEEE Trans. Antennas Propag., Jan. 2015. 